\title{
Depth variation of seismic moment and recurrence interval in Japan
}

\author{
Yingfeng $\mathrm{Ji}^{1,2,3^{*}}$ (D) and Shoichi Yoshioka ${ }^{4,5}$
}

\begin{abstract}
In repeating seismic event sequences within a specialized horizontal area, the moment magnitude is usually scaled with the recurrence interval. In addition to two horizontal dimensions, the vertical dimension plays a certain role in affecting the scaling law. However, whether and how the changing depth influences the scaling law remain enigmatic. Based on a large number of earthquake records with high-resolution epicenter locations in recent decades in Japan, we focus on a comparison between the 3-D seismic moment and seismic interval, which recognize the vertical dimension as the same dimension as the horizontal distances. The results show that (1) the seismic moment scaling law is applicable in the multiparameter 3-D models by visiting the 1.8 million events collected during a period of 15 years; (2) the vertical dimension of depth plays an important role in the Mo-SI relationship as well as in the variance in the 3-D seismic moment-interval magnitudes; and (3) the seismic moment rate, attributable to the plate convergence rate, varies with area and depth in influencing the regional earthquake recurrence frequency.
\end{abstract}

\section{Introduction}

The relationship between magnitude and cumulative earthquake numbers is understood, and the moment magnitude scale interprets the relationship between the seismic moment and the energy released by earthquakes (e.g., Kanamori 1983). Small repeating events are usually found after a large earthquake, such as the 1984 M6.2 Morgan Hill earthquake (e.g., Peng et al. 2005; Templeton et al. 2009), the 1989 M6.9 Loma Prieta event (e.g., Schaff and Beroza 2004), several subduction zone earthquakes in Japan (e.g., Uchida et al. 2004), and the 2004 M6.0 Parkfield earthquake (e.g., Taira et al. 2009; Lengline and Marsan 2009). Following the 2004 M6 Parkfield earthquake, many of the repeating events were associated with significantly reduced recurrence intervals that systematically increased with time (e.g., Chen et al. 2010). The observed shortened recurrence intervals of a repeating earthquake sequence follow an Omori's law distribution in time, implying accelerated fault traveling

\footnotetext{
*Correspondence: yingfengji@itpcas.ac.cn; 31911431@qq.com

${ }^{1}$ Center of Excellence in Tibetan Plateau Earth Science, Chinese Academy of Sciences, Beijing 100101, China

Full list of author information is available at the end of the article
}

along some faults surrounding the rupture (e.g., Peng et al. 2005; Taira et al. 2009). The systematic temporal variations in the characteristics of repeating earthquake sequences in Parkfield through 20 years of observation (1987-2008) indicate that they are mostly consistent with changes in fault strength (Taira et al. 2009). Half of a population of 17 sequences at Parkfield exhibited similar systematic temporal variations in seismic moment (Mo) and seismic interval (SI) after the Parkfield earthquake (Taira et al. 2009).

However, most previous studies focused on the seismic moment-seismic interval (Mo-SI) relationship (e.g., Eq. 1) are based on a horizontally prescribed area, in which the effect exerted by the third dimension (depth) in the Mo-SI law remains enigmatic. Considering that 1.8 million events of full-range magnitudes cataloged are available from the Japan Meteorological Agency (JMA) from October 1, 1997, to February 28, 2015, and given the strength of our research in 3-D numerical simulation (e.g., Ji et al 2016), we attempt to perform a seismicity statistical study of the dozens of 3-D spherical spatial bins of clustered earthquakes recorded in Japan to investigate whether and how the vertical dimension could play a role in the Mo-SI relationship and to unravel more 
earthquake recurrence properties varying with area and depth in Japan.

\section{Data selection}

In this study, with regard to the continuously increasing high-resolution seismic records of recent decades, we select our study region in Japan between longitudes $132^{\circ} \mathrm{E}$ and $147^{\circ} \mathrm{E}$ and latitudes $32^{\circ} \mathrm{N}$ and $46^{\circ} \mathrm{N}$ and employ a set of 1.8 million events of full-range magnitudes cataloged by the Japan Meteorological Agency (JMA) from October 1, 1997, to February 28, 2015, to enable a deeper exploration of the Mo-SI spatiotemporal relationship based on three-dimensional (3-D) seismicity distribution statistics. Considering that the new seismic travel time table JMA2001 (Ueno et al. 2002) and unification of data from universities, municipalities, and other institutes was put into use from October 1997, we select seismic records after October 1997 that have used the updated travel time table. The magnitude range of the events is full range spanning from -1.4 to 7.3 in this study (Table 1). Based on the method, we focus on the detailed 3 -D distribution of 1,842,626 events cataloged by JMA.

\section{Data processing}

\section{Seismically dense sphere method}

The distances between every two arbitrary events are first calculated. For these events, all other events within a certain range of distances are also counted and understood. Then, every event is taken as the center of a sphere, around which we prescribed a radius of $10 \mathrm{~km}$, to define a spatial range in which all of the adjacent events within $10 \mathrm{~km}(\mathrm{~km})$ are counted. We call this sphere the seismically dense sphere because the sphere is a spatial range used to evaluate the seismicity activity density within it. A radius of $10 \mathrm{~km}$ is adopted because the range of error for hypocenter locations provided in the catalog is at a level of kilometers and the seismogenic fault rupture length for an M5.0 earthquake is approximately $4-5 \mathrm{~km}$ according to the seismic moment estimation. Every seismically dense sphere has an event at its center, and thus, we have 1.8 million seismically dense spheres. The seismically dense spheres with a significantly large event number are therefore counted and ranked. The so-called most seismically dense spheres (SDS) during the study period are shown in the map (Fig. 1), and the parameters are tabulated in Table 1. It is noted that the earthquakes' detection capability is heterogeneous in space and time, i.e., it is generally higher for the land region and gradually becomes lower seaward because most observation stations are located on land. Additionally, the detection capability becomes lower just after the occurrence of large earthquakes.
To avoid the presence of overlapping spheres, we set the lower limit of the distance between every two seismically dense spheres (from one center to another center) to be greater than 0.5 degrees (approximately $50 \mathrm{~km}$ ). Provided two spheres are overlapping, the one with a larger event number will be kept, and the other will be ruled out. Using this method, we ultimately obtained 49 seismically dense spheres with the most clustered event distributions during the study period for this study region.

\section{Maximum seismic interval method}

The seismic interval (SI) used to discuss earthquake recurrence in this study is the time interval between two continuously recorded events, that is, the events with magnitudes of $M \geq M_{\text {min }}\left(M_{\text {min }}\right.$ represents the minimum magnitude of events detectable in the catalog) in the seismically dense spheres. We focus on $\mathrm{M}<4$ (small-sized) earthquakes because there have been 71,789 (3.90\%) M3 events, while the number of M4 events is only 12,553 $(0.68 \%)$ and is easily contaminated by small events. We checked and found that $24.6 \%$ of the M3 events are uncontaminated within the interval, while $90 \%$ of M4 events are contaminated within the interval. To identify uncontaminated events, we observe that the maximum seismic interval (MSI) during a certain period (e.g., a day or a month) could potentially be used because the intervals of M3 events are at an average magnitude of days or 10 days. Due to the existence of pre- and postseismic repeating events (Uchida et al. 2004), the MSI within a month has proven to be a restraining factor regarding the noise of repeating events. Taking this into account, we use MSI as a proxy to measure the magnitude of the approximated real SI of $M<4$ events. In addition, the $\mathrm{M}<4$ small-sized earthquakes compose $99.22 \%$ of all recorded events in this study involving the majority of seismicity, which potentially reflects the major properties of earthquake phenomena. Based on these assumptions, we calculate the seismic recurrence intervals and obtain the maximum interval during 1 day (day-based maximum interval, DMSI) or 1-month periods (month-based maximum interval, MMSI). The MMSI is filtered from the SI data using a time window threshold of 1 month (nearly $3.0 \times 10^{6} \mathrm{~s}$ ) over the whole period, while the DMSI is defined within a time window of 1 day. Although both the DMSI and MMSI reflect the real SI, MMSI possesses higher resolution than DMSI. This enables us to further investigate the Mo-SI relation of regular repeating earthquakes without being affected by clustered seismic events and aftershocks.

\section{Seismic moment and interval data source}

The seismic moments of events are provided by JMA. Most of the recorded seismic magnitudes determined by JMA 
Table 1 Parameters and results of the seismically dense spheres (SDS) in this study

\begin{tabular}{|c|c|c|c|c|c|c|c|c|c|}
\hline SDS & Lon $\left(^{\circ}\right)$ & Lat $\left({ }^{\circ}\right)$ & Dep (km) & Events $^{1}$ & Min mag & Max mag & $b$-value ${ }^{2}$ & $k$-value ${ }^{3}$ & PPMCC $^{4}$ \\
\hline 1 & 139.971 & 37.740 & 8.65 & 52,965 & -0.6 & 4.6 & 0.99 & 1.52 & 0.798 \\
\hline 2 & 135.168 & 34.160 & 6.35 & 36,082 & -1.3 & 4.5 & 0.85 & 1.77 & 0.829 \\
\hline 3 & 133.317 & 35.316 & 9.26 & 27,752 & -1.2 & 7.3 & 0.71 & 2.12 & 0.816 \\
\hline 4 & 140.600 & 36.767 & 6.97 & 25,599 & -0.4 & 6.1 & 0.90 & 1.66 & 0.662 \\
\hline 5 & 140.882 & 39.043 & 7.51 & 23,835 & -0.6 & 7.2 & 0.98 & 1.53 & 0.684 \\
\hline 6 & 137.576 & 35.901 & 7.83 & 23,738 & -1.1 & 4.7 & 0.99 & 1.51 & 0.841 \\
\hline 7 & 139.149 & 34.959 & 5.52 & 23,689 & -1.4 & 5.9 & 1.06 & 1.42 & 0.749 \\
\hline 8 & 141.638 & 38.860 & 67.22 & 20,684 & -0.4 & 7.1 & 0.95 & 1.58 & 0.821 \\
\hline 9 & 139.404 & 36.639 & 7.90 & 18,777 & -1.1 & 4.8 & 0.99 & 1.52 & 0.821 \\
\hline 10 & 139.290 & 34.184 & 13.91 & 14,359 & 0.0 & 6.5 & 0.61 & 2.44 & 0.676 \\
\hline 11 & 140.911 & 35.744 & 13.46 & 12,501 & 0.0 & 6.1 & 0.89 & 1.68 & 0.709 \\
\hline 12 & 138.930 & 37.325 & 9.47 & 11,157 & -0.7 & 6.8 & 0.97 & 1.55 & 0.900 \\
\hline 13 & 135.542 & 34.978 & 9.85 & 11,088 & -0.8 & 4.4 & 1.00 & 1.50 & 0.838 \\
\hline 14 & 136.716 & 37.261 & 7.23 & 10,274 & -0.6 & 6.9 & 0.96 & 1.56 & 0.896 \\
\hline 15 & 140.500 & 39.992 & 6.31 & 9223 & -0.7 & 4.9 & 1.01 & 1.48 & 0.722 \\
\hline 16 & 140.915 & 36.264 & 41.94 & 8310 & 0.0 & 5.2 & 0.89 & 1.68 & 0.831 \\
\hline 17 & 134.515 & 35.511 & 7.74 & 8173 & -0.6 & 5.6 & 1.02 & 1.47 & 0.754 \\
\hline 18 & 135.676 & 33.944 & 11.10 & 7622 & -0.9 & 4.1 & 1.08 & 1.39 & 0.710 \\
\hline 19 & 141.137 & 38.435 & 8.58 & 7558 & -0.6 & 6.4 & 0.99 & 1.51 & 0.832 \\
\hline 20 & 142.390 & 39.150 & 31.61 & 6730 & 0.0 & 6.2 & 0.93 & 1.61 & 0.680 \\
\hline 21 & 142.992 & 43.423 & 5.69 & 6518 & -1.2 & 4.2 & 0.88 & 1.71 & 0.757 \\
\hline 22 & 139.018 & 35.479 & 21.55 & 5907 & -0.8 & 5.4 & 0.97 & 1.54 & 0.852 \\
\hline 23 & 140.099 & 35.636 & 65.47 & 5851 & 0.0 & 5.3 & 0.90 & 1.66 & 0.845 \\
\hline 24 & 142.171 & 38.398 & 30.26 & 5844 & 0.0 & 5.3 & 0.90 & 1.66 & 0.648 \\
\hline 25 & 137.668 & 36.514 & 2.05 & 5680 & -0.7 & 5.4 & 1.03 & 1.45 & 0.796 \\
\hline 26 & 136.177 & 34.349 & 8.06 & 5528 & -0.9 & 4.1 & 1.03 & 1.45 & 0.761 \\
\hline 27 & 138.645 & 36.824 & 5.60 & 5303 & -0.4 & 5.6 & 1.00 & 1.50 & 0.833 \\
\hline 28 & 133.818 & 35.372 & 9.74 & 4956 & -1.2 & 5.5 & 1.04 & 1.44 & 0.792 \\
\hline 29 & 137.889 & 34.874 & 17.92 & 4779 & -0.8 & 4.2 & 1.01 & 1.48 & 0.845 \\
\hline 30 & 139.984 & 37.239 & 7.28 & 4623 & -0.5 & 5.7 & 1.01 & 1.48 & 0.699 \\
\hline 31 & 137.325 & 35.033 & 37.28 & 4587 & -0.5 & 4.0 & 1.02 & 1.47 & 0.910 \\
\hline 32 & 132.816 & 35.002 & 8.78 & 4184 & -1.2 & 4.6 & 0.78 & 1.92 & 0.780 \\
\hline 33 & 134.697 & 34.925 & 14.07 & 4149 & -0.8 & 4.0 & 1.01 & 1.48 & 0.822 \\
\hline 34 & 140.012 & 36.149 & 60.77 & 3921 & -0.1 & 5.4 & 0.93 & 1.61 & 0.881 \\
\hline 35 & 142.159 & 39.677 & 41.90 & 3810 & -0.4 & 5.9 & 0.94 & 1.59 & 0.746 \\
\hline 36 & 141.267 & 36.767 & 41.78 & 3661 & 0.0 & 5.8 & 0.79 & 1.89 & 0.835 \\
\hline 37 & 140.633 & 38.285 & 12.38 & 3522 & -0.1 & 3.7 & 1.00 & 1.50 & 0.733 \\
\hline 38 & 144.695 & 43.697 & 6.03 & 3442 & -0.4 & 4.8 & 0.96 & 1.56 & 0.792 \\
\hline 39 & 139.308 & 41.958 & 9.49 & 3402 & -0.2 & 4.2 & 0.95 & 1.58 & 0.803 \\
\hline 40 & 141.790 & 37.357 & 36.93 & 3242 & 0.0 & 6.2 & 0.84 & 1.78 & 0.797 \\
\hline 41 & 135.930 & 35.479 & 11.57 & 2957 & -1.1 & 4.5 & 1.01 & 1.48 & 0.817 \\
\hline 42 & 138.465 & 34.832 & 20.46 & 2837 & -0.3 & 6.5 & 0.97 & 1.55 & 0.768 \\
\hline 43 & 142.660 & 39.661 & 29.65 & 2751 & 0.0 & 6.4 & 0.82 & 1.84 & 0.755 \\
\hline 44 & 132.689 & 33.481 & 34.60 & 2598 & -0.6 & 3.7 & 0.89 & 1.68 & 0.718 \\
\hline 45 & 141.694 & 44.104 & 5.80 & 2430 & -0.4 & 6.1 & 1.00 & 1.50 & 0.815 \\
\hline 46 & 136.819 & 35.444 & 12.51 & 2371 & -0.7 & 3.5 & 0.99 & 1.51 & 0.831 \\
\hline 47 & 138.089 & 35.884 & 8.83 & 2185 & -1.0 & 3.6 & 0.94 & 1.59 & 0.803 \\
\hline 48 & 134.534 & 33.855 & 9.78 & 2144 & -0.8 & 4.5 & 0.91 & 1.64 & 0.792 \\
\hline 49 & 144.004 & 43.363 & 16.85 & 2052 & -0.8 & 4.1 & 1.06 & 1.41 & 0.812 \\
\hline
\end{tabular}




\section{Table 1 (continued)}

\footnotetext{
1 The numbers of the seismic events from October 1, 1997 to February 28, 2015, in a full-magnitude range occurring within each SDS according to the catalog of the JMA. The full-range magnitude of events is adopted for each SDS

2 The completeness magnitude Mc is largely influenced by the station density, and the use of the earthquakes with magnitudes of 1.9 or larger above possibly covers a complete catalog (Nanjo et al. 2010). The b-value estimation in Table 1 includes $M<$ Mc events and has an uncertainty due to the event detectability

3 The parameters of Eq. 1 in the main text. The variable $\mathrm{k}$ is a dimensionless value. The unit of $\mathrm{c}$ is $\left(\mathrm{Nms}^{-1}\right)$

${ }^{4}$ The Pearson product-moment correlation coefficient (PPMCC) of the logarithm of the seismic moment and seismic interval for each SDS
}

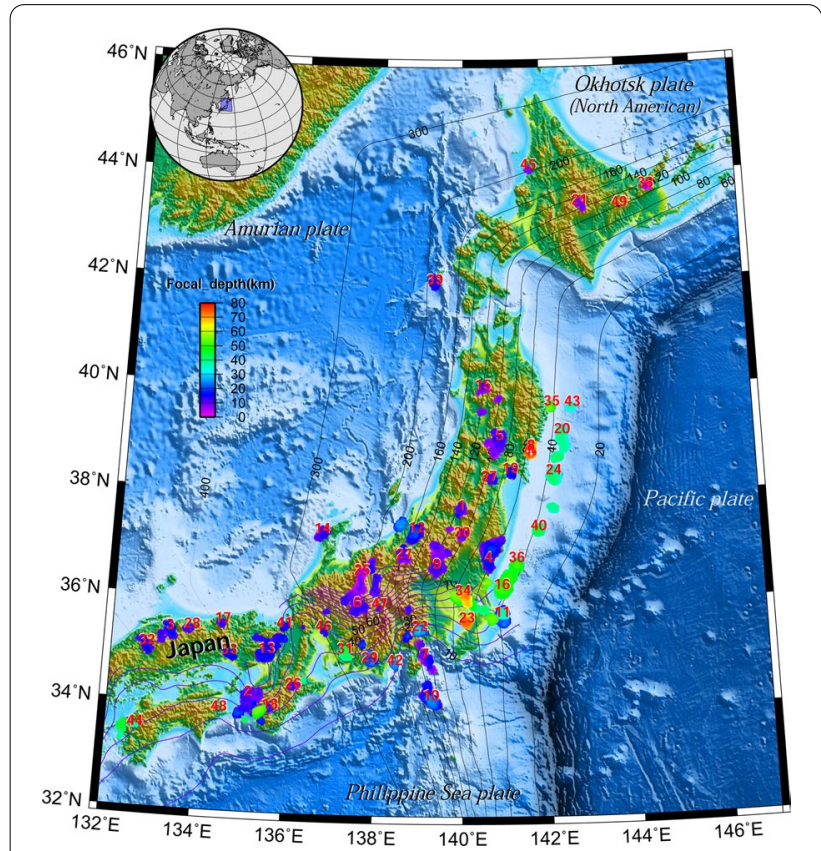

Fig. 1 Spatial distribution of the 49 seismically dense spheres (SDS). The background color is the surface elevation $(\mathrm{km})$ from the Etopo digital elevation model (Smith and Sandwell 1997). The black and violet lines indicate the iso-depth $(\mathrm{km})$ contours of the upper surface of the subducted Pacific (PAC) and Philippine Sea (PHS) plates (Nakajima and Hasegawa 2007). The overlapping colored circles marked by numbers 1 to 49 are the seismically dense spheres targeted in this study

use the moment magnitude scale or the JMA magnitude scale, which is almost equivalent to a moment magnitude for a seismic event (Utsu 1983; Katsumata 1996). The intervals are calculated between two recorded events according to the JMA catalog. The large number of earthquake records observed within the high-density seismic observation network presents a good foundation for the study of the Mo-SI scaling law as well as further correlation analyses and investigations of the variance in Mo-SI magnitudes associated with changes in area and depth.

\section{Results}

The logarithms of the seismic moments and seismic intervals of successive events within the 49 seismically dense spheres are shown in Figs. 2, 3, 4, 5, 6, 7, 8. The distributions of the SI logarithm in most of the spheres (Figs. 2, 3, 4, 5, 6, 7, 8) have two typical but different stages (especially for the spheres located near the source region of the M9.0 Tohoku earthquake), which are possibly influenced by the most recent large earthquakes. One is a sparsely distributed period that is mostly irregular (e.g., Fig. 2a before September 2001), and the other is a densely distributed period (e.g., Fig. 2a after September 2001 and lasting for almost 10 years until 2011). In the densely distributed period, the variation in the SI values in its upper part coincides with the variation in the recorded seismic moment (Figs. 2a, 3, 4, 5, 6, 7, 8). The majority of the seismic frequencies that transition from a sparsely to densely distributed period sometimes appears to be synchronized with seismic events $(M>5$, only for a comparison with the peripheral large earthquakes) within or outside the spheres within a distance of $500 \mathrm{~km}$. However, it is sometimes difficult to determine whether they are correlated, as depicted by the pink open circles in the upper part of Figs. 2, 3, 4, 5, 6, 7, 8. The seismicity within a distance of $500 \mathrm{~km}$ peripherally can possibly influence the occurrence of earthquakes inside the spheres, and sometimes the minimum seismic interval drops to a level of minutes, but the maximum seismic interval is not influenced by seismic swarms or repeating earthquakes. The monthly maximum SI is plotted as the cyan curve in Fig. 2a. The results reveal a correlation between the seismic magnitude variation (pink curve) and the monthly maximum SI variation (cyan curve) in the sampled spheres (e.g., Fig. 2a).

A similar correlation for moment and monthly maximum SI can also be found in the 49 seismically dense spheres spanning a wide range of regions from southwest Japan to Hokkaido (Fig. 1), with a comparatively acceptable confidence level (Table 1). This pattern indicates that a potential law likely governs this phenomenon because a great number of events have been included in the analysis. For example, the dense seismic sphere SDS1 with the largest event number 52965 during the period of October 1, 1997, to February 28, 2015, has its center located at $37.740^{\circ} \mathrm{N}, 139.971^{\circ} \mathrm{E}$ with a depth of $8.65 \mathrm{~km}$ (the radii of the spheres are all $10 \mathrm{~km}$ in Table 1), adjacent to the Bandaishan volcano in the inland Fukushima Prefecture (Fig. 1). The hypocenter is shallow in the upper crust, and all of the repeating events occur shallower than $18.65 \mathrm{~km}$ 


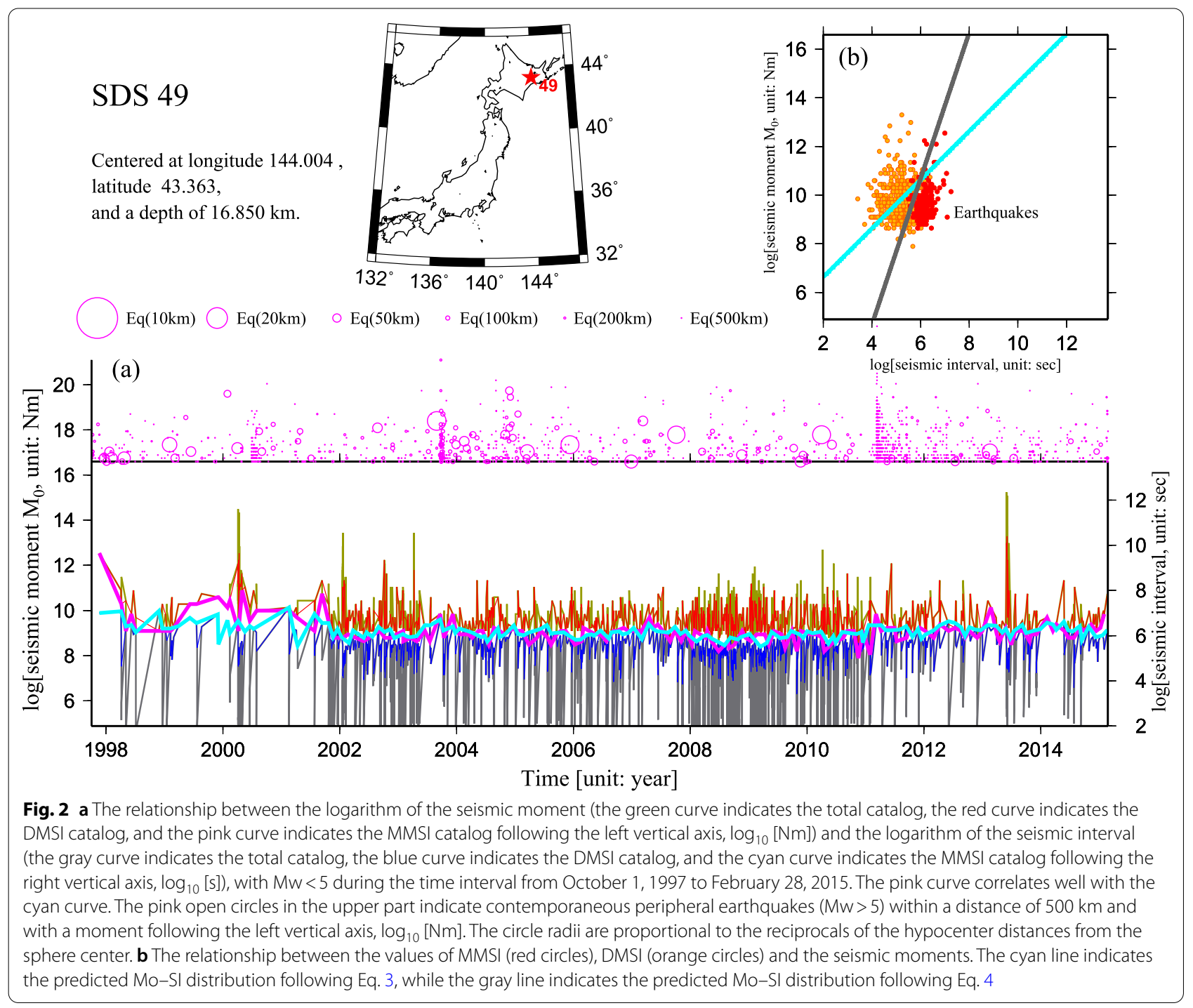

$(8.65+10 \mathrm{~km})$. The a-value is -5.63 , the $b$-value is 0.99 , and the $k$-value is 1.52 , which indicate that the seismic moment is proportional to the seismic interval to a power of 1.52. The Pearson product-moment correlation coefficient (PPMCC) of the logarithm of the seismic moment and seismic interval for SDS1 is 0.798, which indicates the confidence level. Most of the 49 seismically active zones feature $b$-values of approximately $0.82-1.08$, except SDS3 (0.71, western Tottori), SDS32 (0.78, northern Hiroshima) and SDS36 (0.79, offshore Ibaraki). The $b$-values of these study regions are approximated to be close to 1.

In addition, nearly all of the centers of these seismically active zones are located in the upper crust $(<20 \mathrm{~km})$ inland (intraplate earthquakes) or at a depth of $30-60 \mathrm{~km}$ offshore (interplate earthquakes). Exceptions are that SDS23
(65.47 km, Tokyo) and SDS34 (60.77 km, southern Ibaraki) are inland but influenced by overlapping subduction of the Pacific plate and Philippine Sea plate at a depth of $60-80 \mathrm{~km}$, and SDS31 (37.28 km, eastern Aichi) and SDS44 (34.60 km, western Ehime) are also inland but in the lower crust, which is probably facilitated by upwelling fluids/ melts from the subducted Philippine Sea plate at a depth of approximately $60 \mathrm{~km}$ beneath.

Figures 2, 3, 4, 5. 6, 7, 8 show that the seismic moment (red curves in the upper part of Fig. a) and seismic intervals (blue curves in the lower part of Fig. a) have an approximately scaling relationship in magnitude. The variation in the magnitude of the seismic moment is usually accompanied by a simultaneous similar variation in the magnitude of the seismic interval in all 49 study regions. This scaling phenomenon is found not only among the intraplate 
(See figure on next page.)

Fig. 3 Calculated results of seismic moment and seismic interval at the selected regions of seismically dense spheres 1-8. The relationship between the logarithm of the seismic moment (red curve, left vertical axis, log[Nm]) and the logarithm of the seismic interval (blue curve, right vertical axis, $\log [s]$ ) during the period from October 1, 1997 to February 28, 2015. The pink circles in the upper part are the contemporaneous Mw $>5$ earthquakes outside of the seismically dense spheres, which may potentially influence the seismicity inside. The upper right box indicates the relationship between the seismic moment and the seismic interval in the Mo-SI diagram. Orange points indicate the events immediately after a day-based maximum seismic interval (DMSI). Red points indicate the events immediately after a month-based maximum seismic interval (MMSI). The cyan line indicates the predicted Mo-SI distribution following Eq. 3, while the gray line indicates the predicted Mo-SI distribution following Eq. 4

earthquakes in the upper crust but also among the subduction earthquakes at depth. The b-value does not change much between the two types of earthquakes or at various depths. Since sphere-shaped regions with radii as small as $10 \mathrm{~km}$ are prescribed in this study, the results indicate that the scaling law for seismic moment and seismic interval stands for the third dimension of depth, which could be regarded as the same as the horizontal dimensions and distances. That is, the 3-D dimensions are applicable to the G-R law and Mo-SI scaling law. The seismically dense spheres within the same region or at the same depth added together still comply with the Mo-SI scaling law, which has been recognized in many previous studies, although the a-value and b-value vary with changes in area or depth. From this angle, we understand that the 3-D-based G-R law and Mo-SI scaling law are reasonable extensions of the traditional 2-D-based perspective, which reflects the essence of the G-R law and Mo-SI scaling law.

\section{Discussion}

\section{Comparison with Mo-SI relationship}

Combining the moment magnitude scale law $\log _{10}\left(M_{o}\right) \approx 1.5 M_{w}+9.09$ (Hanks and Kanamori 1979) with the Gutenberg-Richter law $\log _{10} N=\mathrm{a}-\mathrm{bM}$ (Gutenberg and Richter 1956), we have

$$
M_{o} \approx \mathrm{cT}^{\mathrm{k}}=10^{\frac{3 \mathrm{a}}{2 \mathrm{~b}}+9.09} \mathrm{~T}^{\frac{3}{2 \mathrm{~b}}}
$$

where $M_{0}$ is the seismic moment, $\mathrm{c}$ is the earthquake moment rate, $\mathrm{c}=10^{\frac{3 \mathrm{a}}{2 \mathrm{~b}}+9.09}, \mathrm{~T}$ is the average seismic interval (unit: $\mathrm{s}$ ), $\mathrm{a}$ and $\mathrm{b}$ are the coefficients in the Gutenberg-Richter law, and $\mathrm{k}=\frac{3}{2 \mathrm{~b}}$ (see Additional file 1: "Explanation for Eq. 1"). Equation 1 interprets the relationship we observed between the logarithm of the seismic moment and MSI in the observed seismically dense spheres (Figs. 2, 3, 4, 5, 6, 7, 8). In addition, assuming that $\mathrm{k}$ is 1 and $\mathrm{c}=\frac{\mathrm{M}_{\mathrm{o}}}{\mathrm{T}} \approx 10^{4}-10^{6}\left(\mathrm{Nms}^{-1}\right)$, which is equivalent to fewer than 100 earthquakes with $\mathrm{Mw} \geq 1.0$ recurring every day, we have

$$
\log _{10}\left(M_{o}\right)=\log _{10}(T)+\log _{10}(\mathrm{c}) \approx \log _{10}(T)+4 \sim 6,
$$

which shows that if a giant earthquake occurs within $500 \mathrm{~km}$, the value of $\log \mathrm{c}$ may reach $7-8$, resulting in a larger gap between the curves of SI and magnitude (e.g., seismically dense sphere 24 ).

If we consider the definition of the seismic moment $M_{o}=\mu D L^{2}$, where $\mu$ is the fault rigidity or fragility $(\mathrm{Pa})$, $D$ is the average slip amount $(\mathrm{m})$, and $L$ is the rupture length of a fault $(\mathrm{m})$, and assume a seismic load rate $v$ $(\mathrm{m} / \mathrm{s})$ during the period of a seismic interval SI $(\mathrm{T})$, then $D=v T$, and the seismic moment can be described as:

$$
M_{o}=\mu L^{2} v T .
$$

If the seismic load rate $v$ and the fault rupture length $L$ are constant, then the seismic moment $M_{0}$ will scale to $T(\mathrm{SI})$ by c $\left(\mathrm{c}=\mu L^{2} v\right)$. The c-value is proportional to the seismic load rate $v$, the fault rigidity or fragility $\mu$ and the fault rupture length $L$, which are assumed to be correlated with the fault strength. This correlation can be used to interpret the observed Mo-SI relationship coincidentally from the slope of the seismic moment. Assuming that $\mu$ is $30 \mathrm{GPa}, L$ is $30 \mathrm{~m}$ for $\mathrm{Mw}=1$ (i.e., $\log \mathrm{Mo}=10.6$, which is the rough average magnitude in seismically dense sphere 49, as shown in Fig. 2), and $\mathrm{v}$ is $0.05 \mathrm{~m} /$ year, we can infer $\mathrm{c}=\mu \mathrm{L}^{2} \mathrm{v}=4.28 \times 10^{4}\left(\mathrm{Nms}^{-1}\right)$, whose logarithm is 4.63 , which complies with the empirical estimate in Eq. 2. The other seismically dense spheres also follow this estimate. For example, $\log M o \approx 11$ in SDS5 (Fig. 3), then $L \approx 41.1 \mathrm{~m}, \mathrm{c}=\mu \mathrm{L}^{2} \mathrm{v}=8.03 \times 10^{4}$ $\left(\mathrm{Nms}^{-1}\right)$, whose logarithm is 4.90 ; logMo $\approx 10$ in SDS7 (Fig. 3), then $L \approx 19 \mathrm{~m}, \mathrm{c}=\mu \mathrm{L}^{2} \mathrm{v}=1.73 \times 10^{4}\left(\mathrm{Nms}^{-1}\right)$, whose logarithm is 4.24 .

\section{Comparison of the different dimensions and b-values of the fault systems}

Different fault systems loaded along various fault planes account for various fault slip behaviors. The direction of the load rate $\mathrm{v}$ is dependent more on the strike and dip of the fault system than on the relative motion of the plate direction. More importantly, the slip behavior probably changes its direction along a curved fault plane during the rupture occurrence. For a 3-D curved fault plane, the rupture length and the area of the ruptured zone likely 

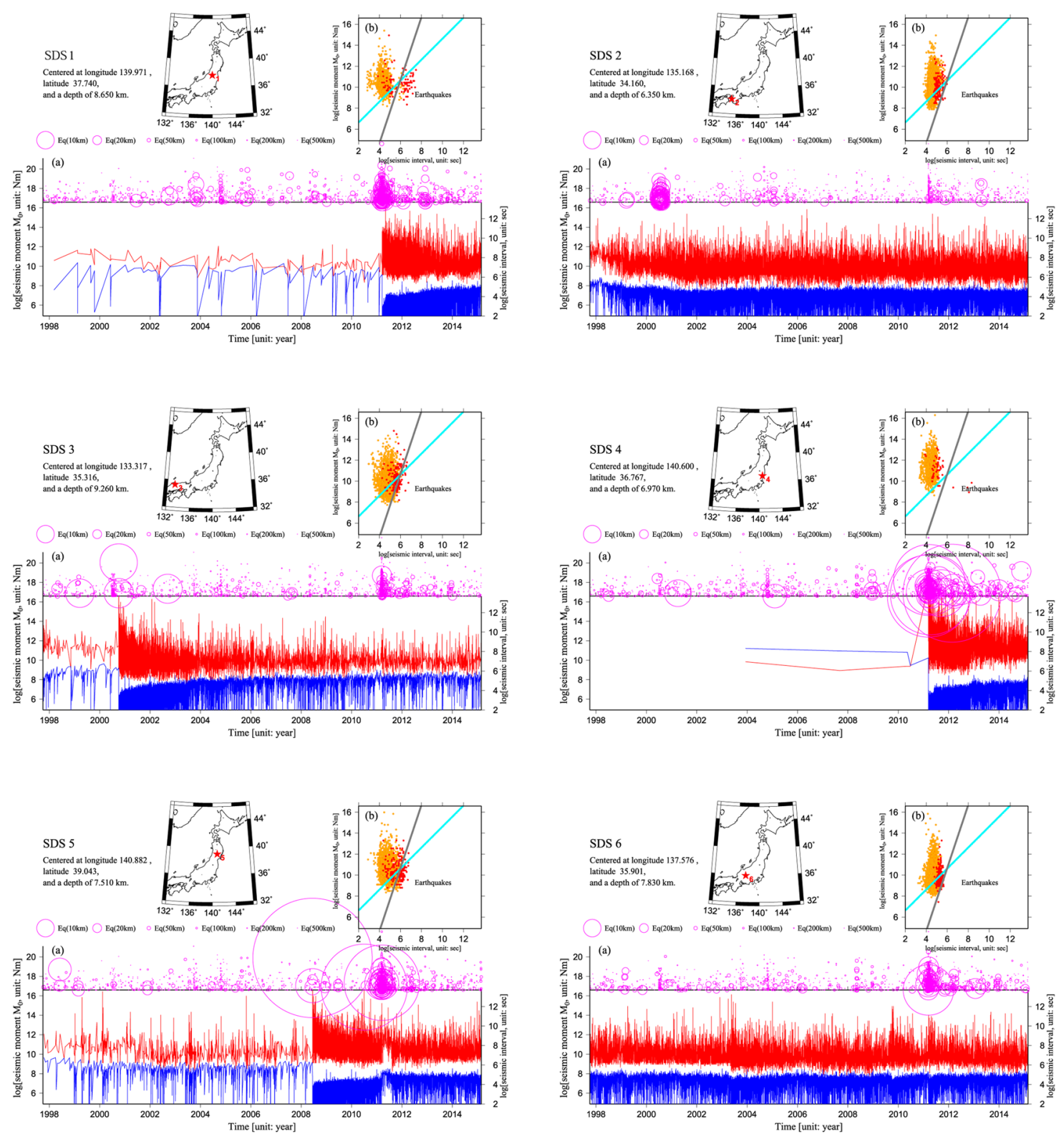
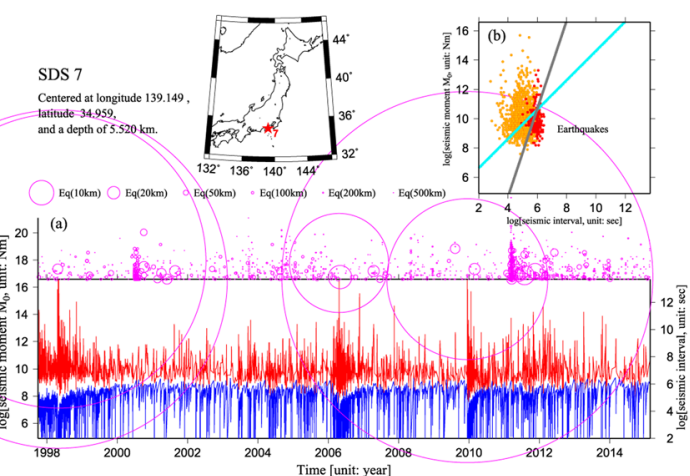
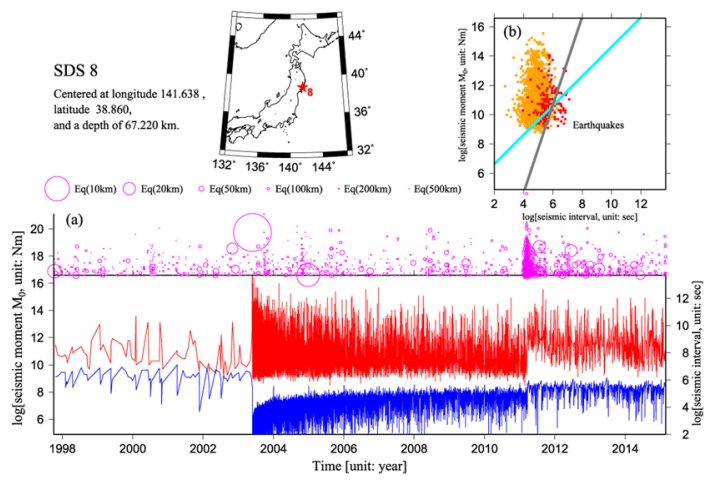

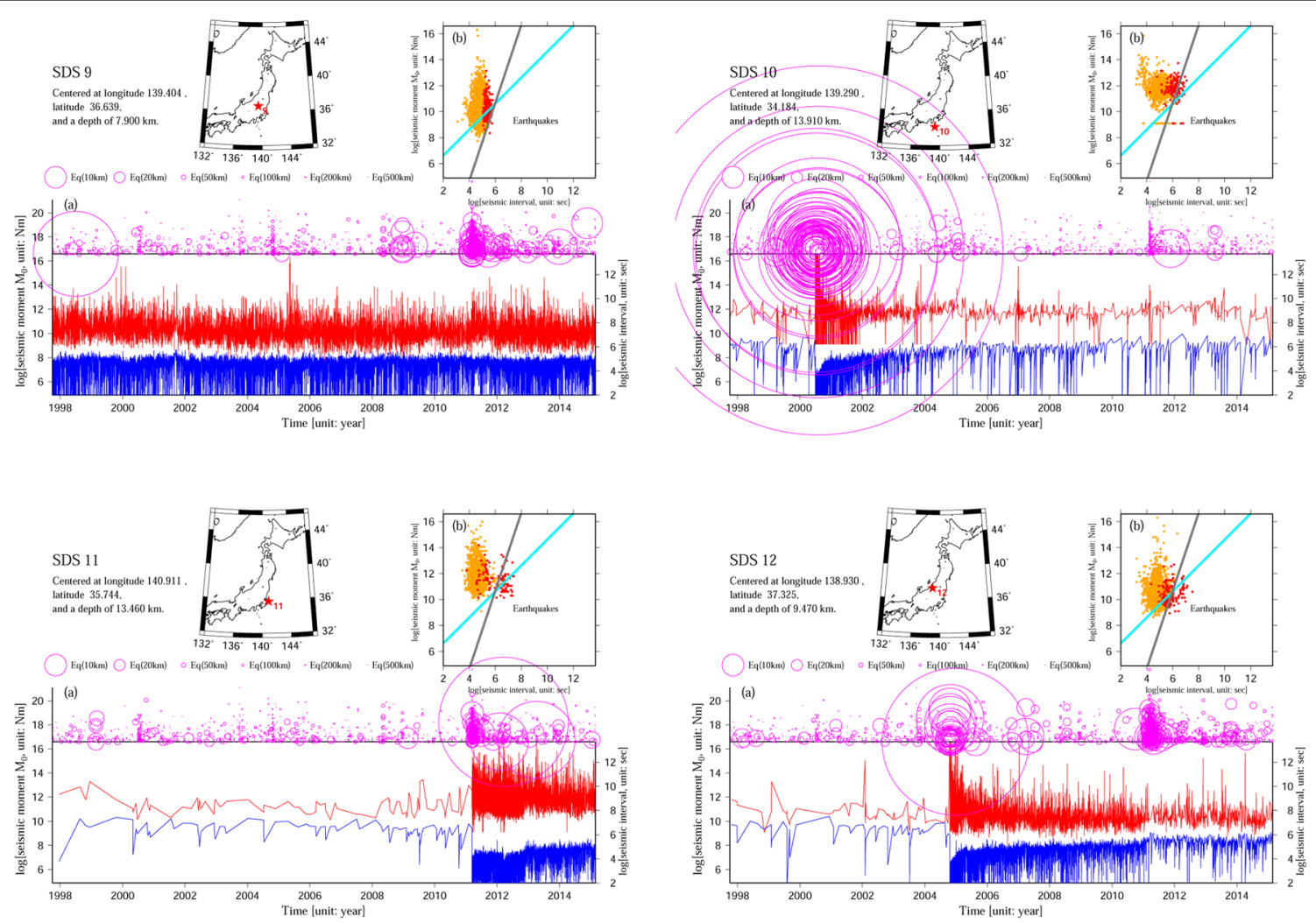
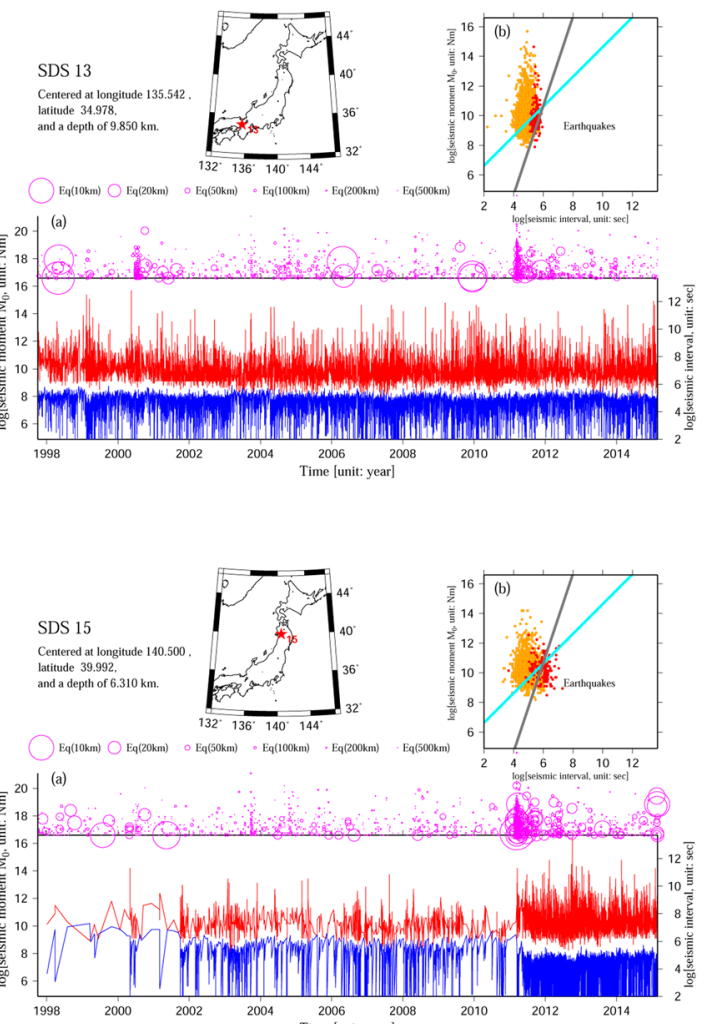
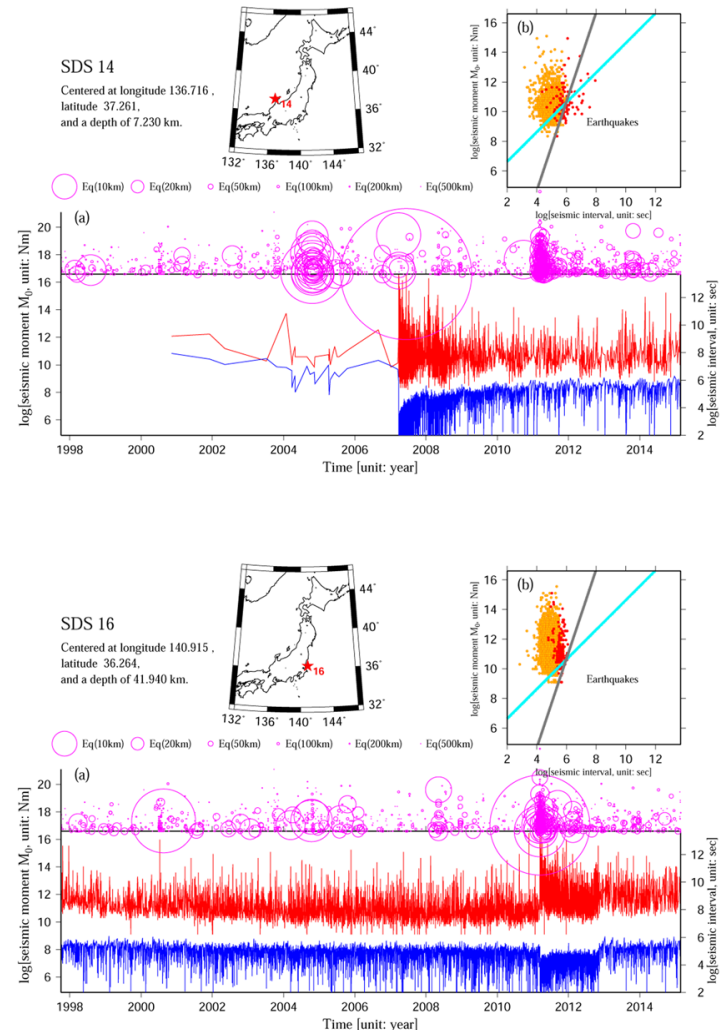

Fig. 4 Calculated results of seismic moment and seismic interval at the selected regions of seismicity density spheres 9-16 

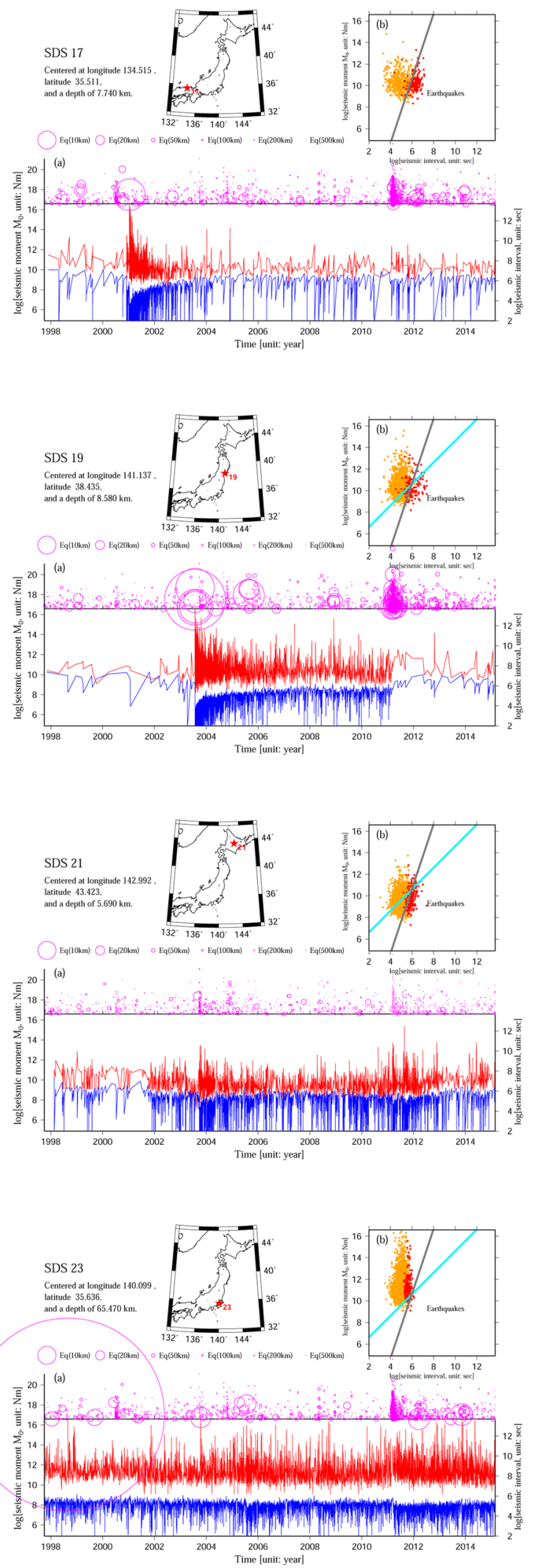
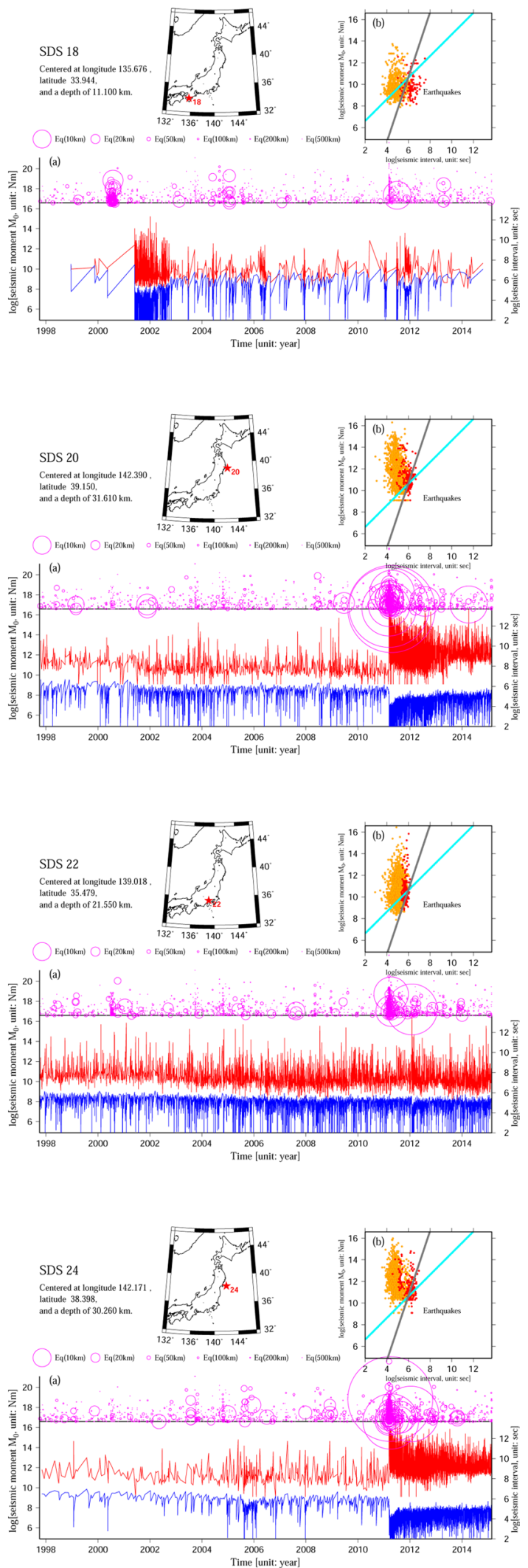

Fig. 5 Calculated results of seismic moment and seismic interval at the selected regions of seismicity density spheres 17-24 

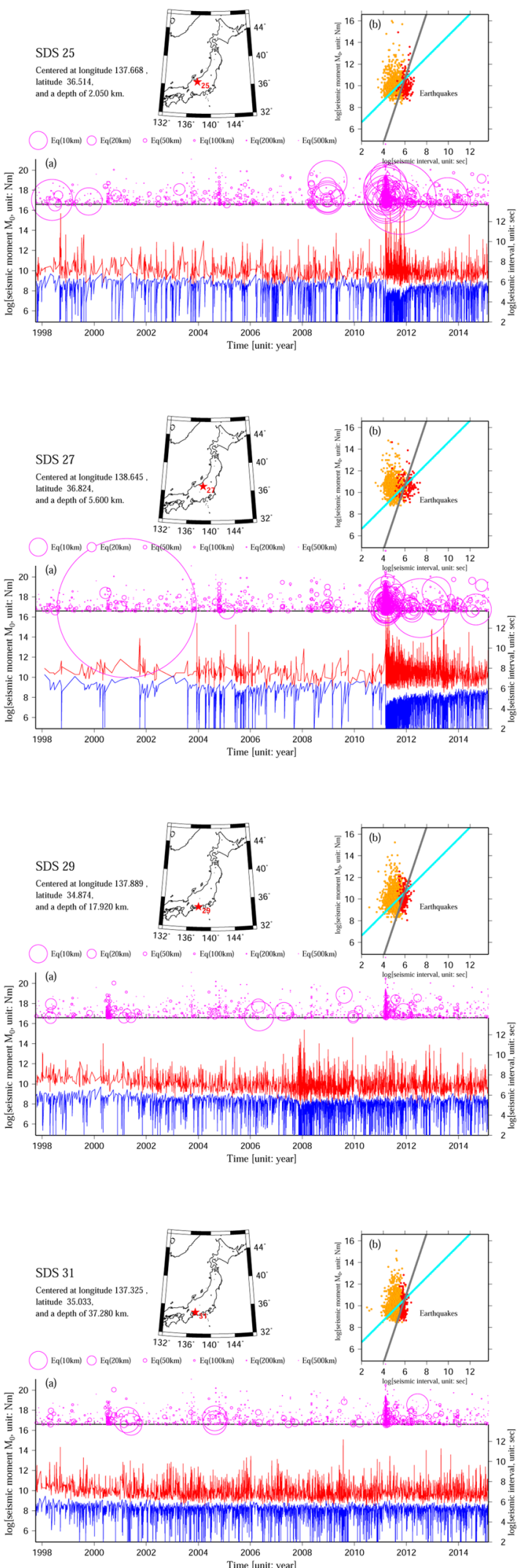
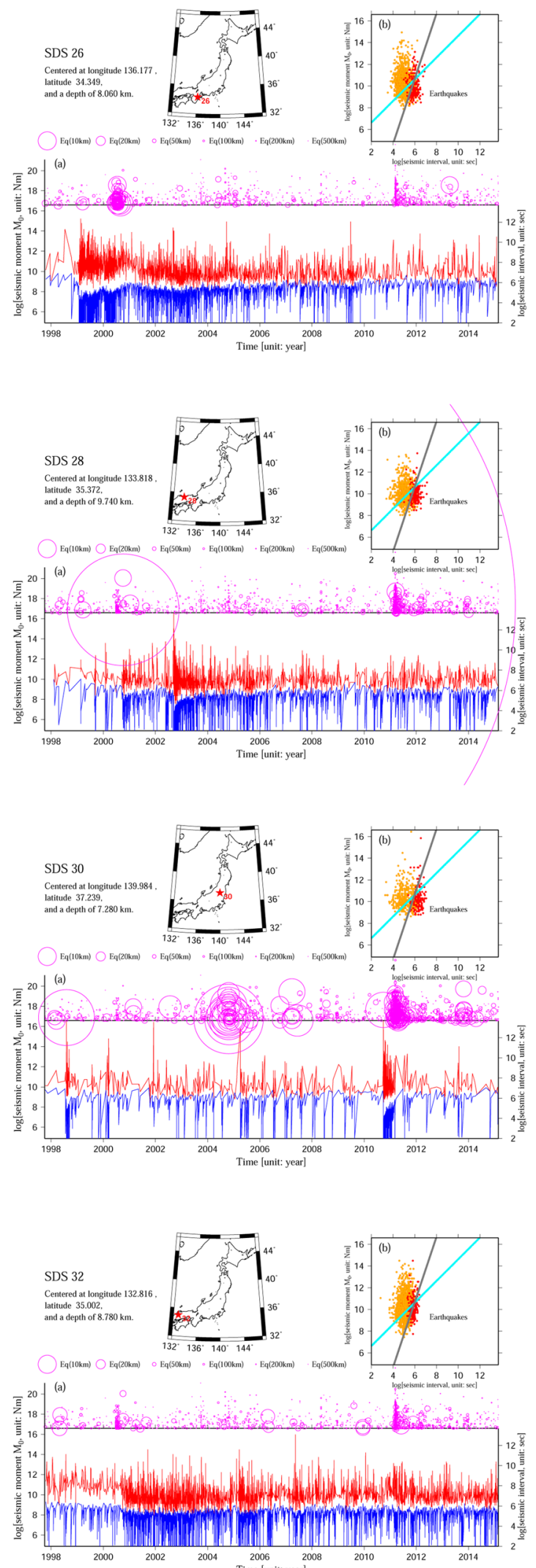

Fig. 6 Calculated results of seismic moment and seismic interval at the selected regions of seismicity density spheres 25-32 

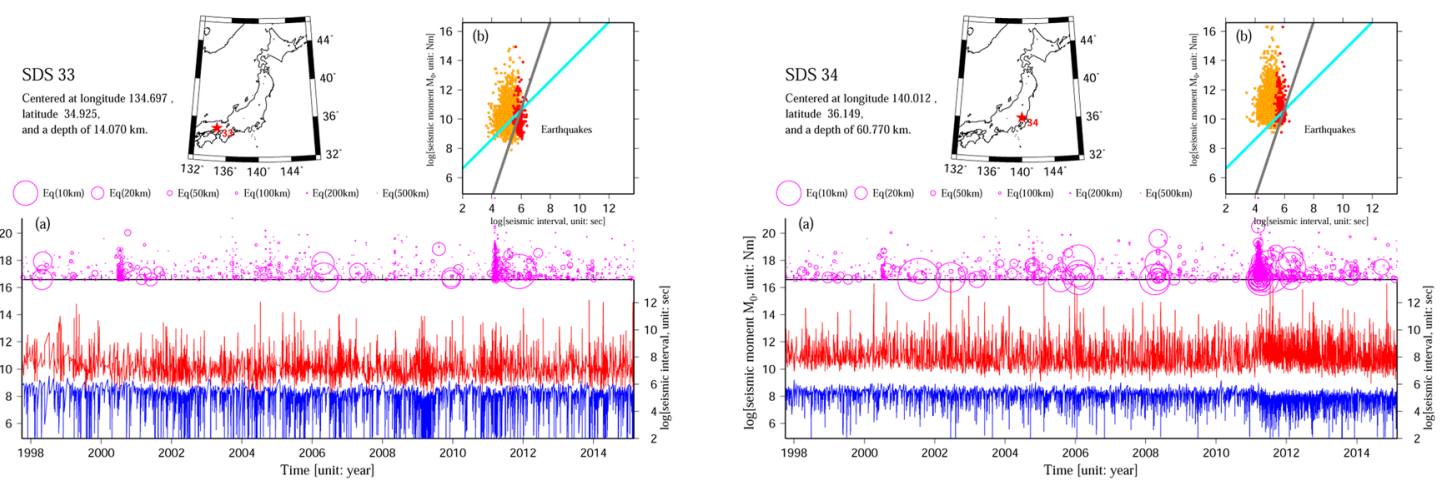

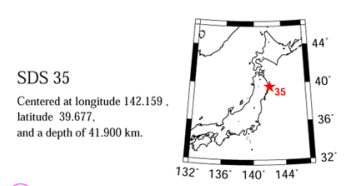

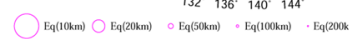
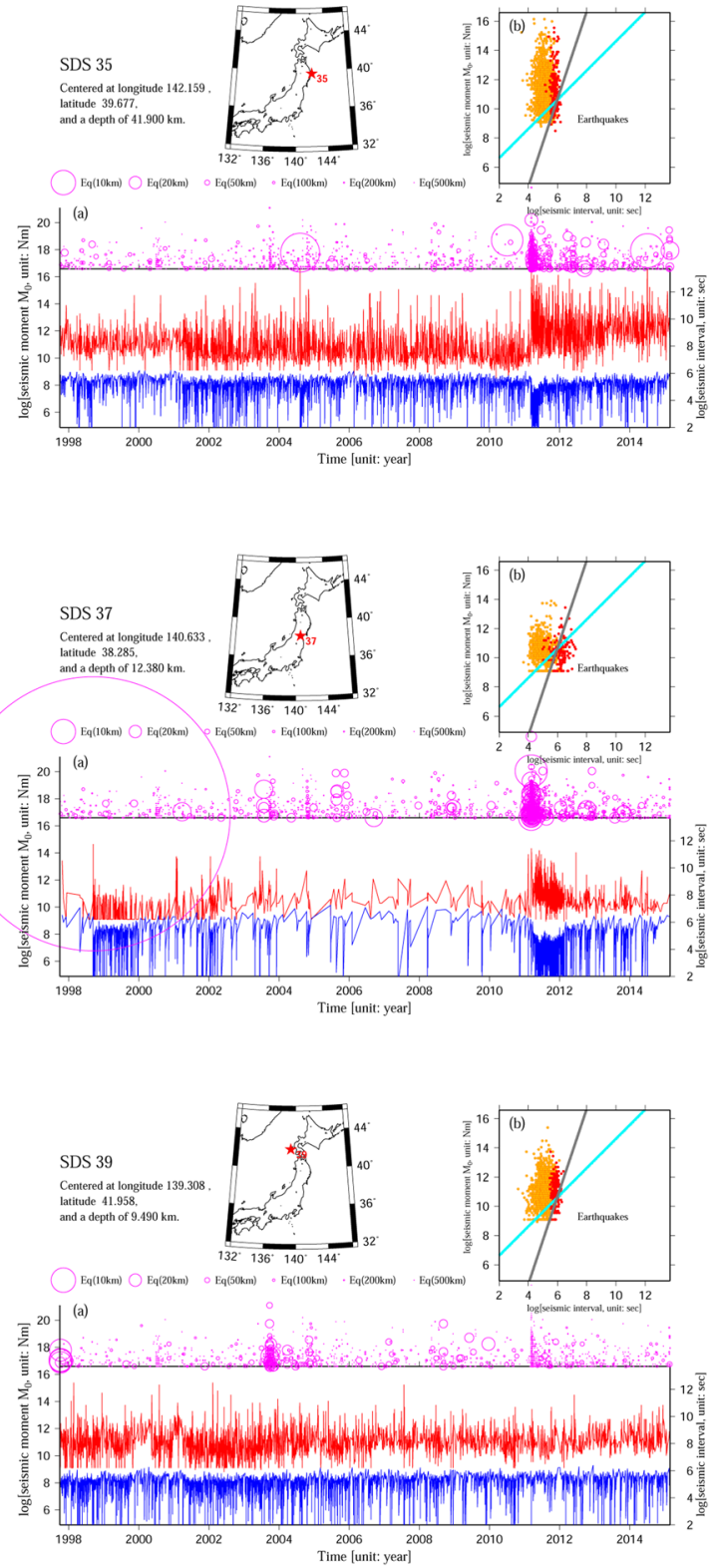
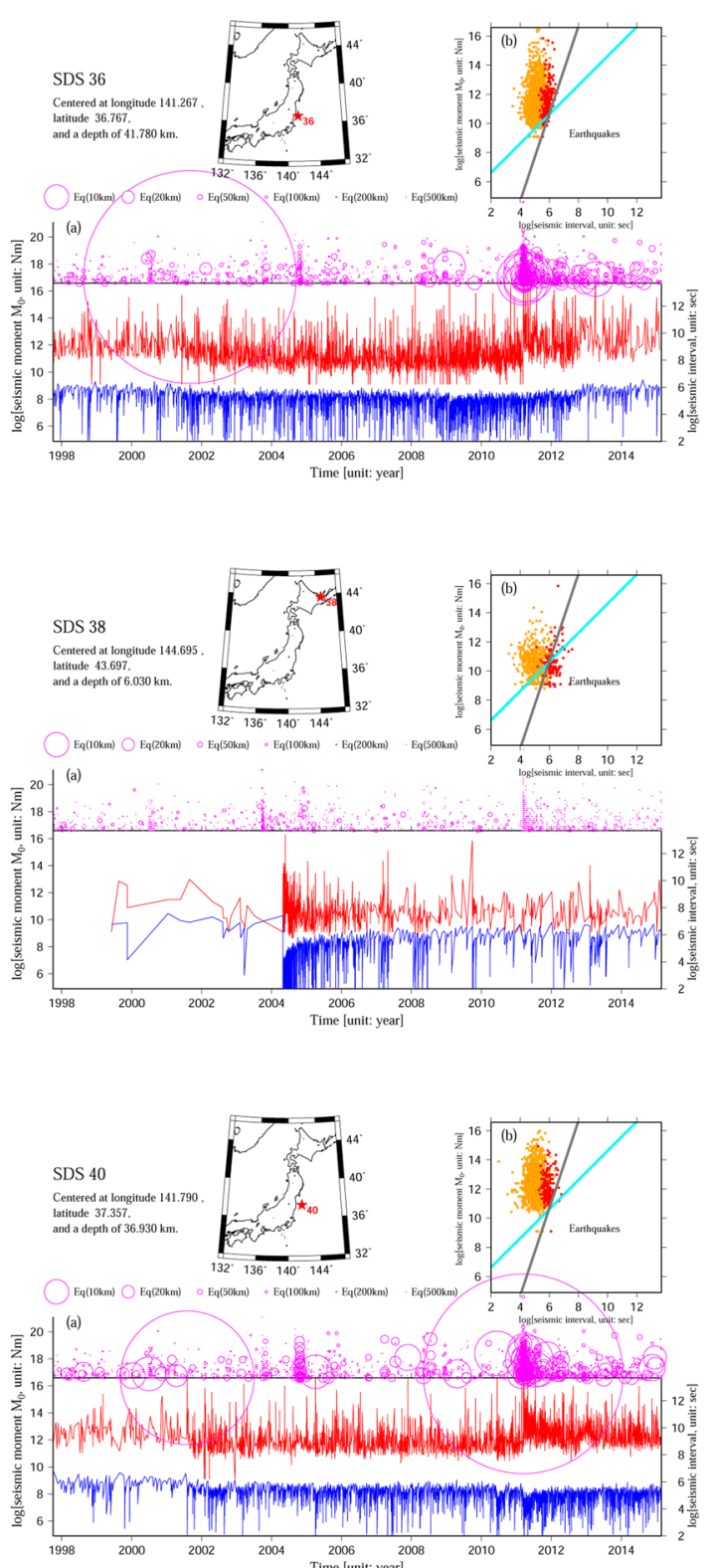

Fig. 7 Calculated results of seismic moment and seismic interval at the selected regions of seismicity density spheres 33-40 

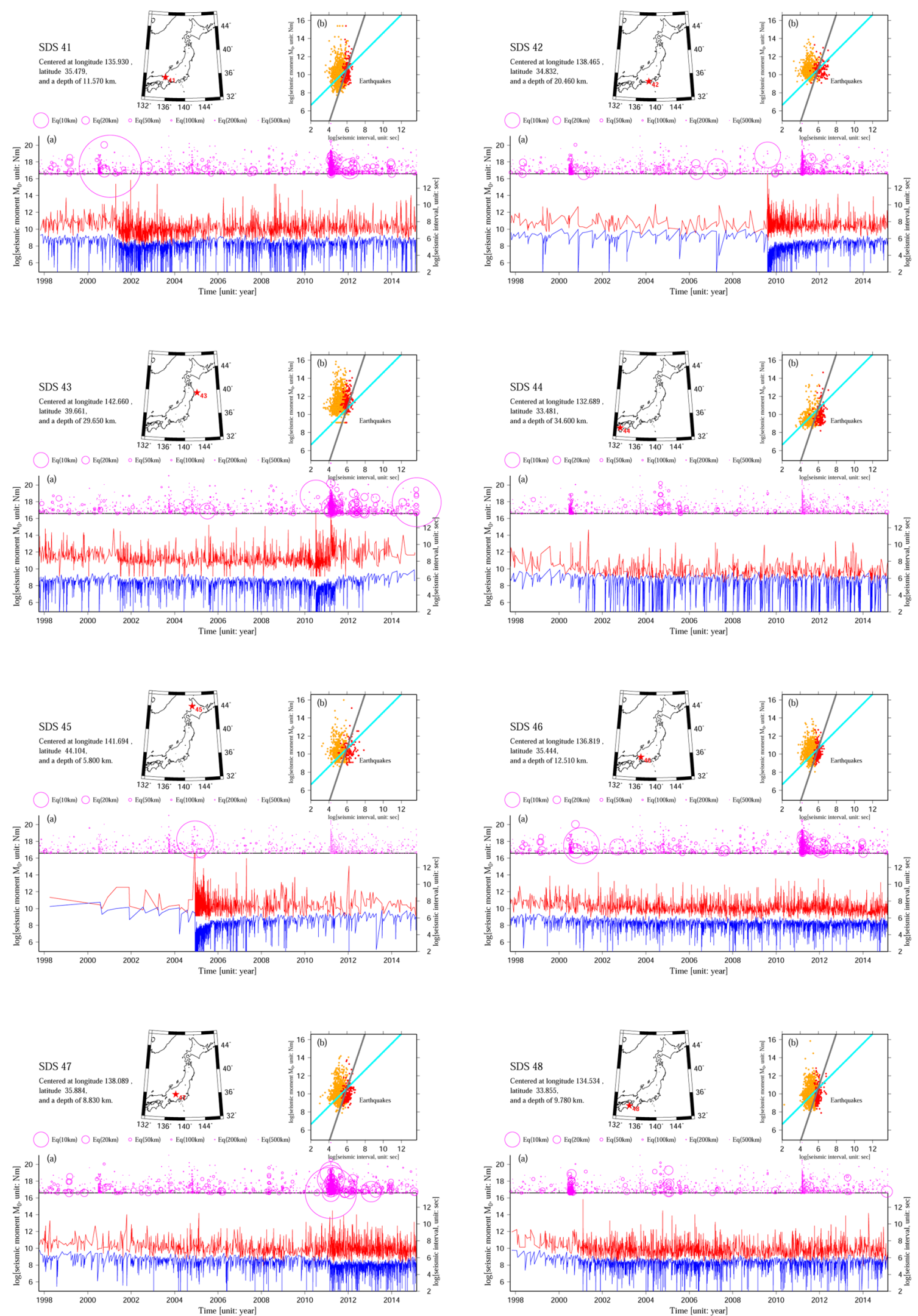

Fig. 8 Calculated results of seismic moment and seismic interval at the selected regions of seismicity density spheres 41-48 
change during fault slip. In this case, $L$ (fault rupture length) is a variable similar to D (slip), and we must consider whether it should be divided by the seismic interval $(\mathrm{T})$. Therefore, the seismic moment rate could also be two- or three-dimensional, involving full ranges of dip, rake and strike.

Compared with $M_{0}=\mathrm{cT}^{\mathrm{k}}$, if we consider the dimension to be $k=3$ (corresponding to $b=0.5$ ) and the fault rupture length $L$ to be approximately proportional to the seismic slip amount $\mathrm{D}$, then we would have a scaling law related to two- and three-dimensional slip behaviors:

$$
M_{o}=\alpha \mu \tau^{-2} v^{3} T^{3},
$$

where $\tau=D / L=E / M_{0}$ is the ratio of the seismic energy and seismic moment, which is proposed to be a constant of $5.0 \times 10^{-5}$ (Kanamori 1983), and $\alpha$ is a proportional coefficient between the rupture length and characteristic length (e.g., Leonard 2010) and is approximately a constant for $M<6$ earthquakes (e.g., Weng and Yang 2017). $\alpha \mu \tau^{-2} v^{3}$ is the seismic moment rate (c-value), and $\mathrm{v}$ is the seismic load rate. Equation 4 has an advantage in that it does not involve the characteristic fault length $L$, which further suggests that the key factor influencing the relationship between the seismic moment and SI is not simply the moment rate but is also the seismic energymoment ratio over a long period. For the MMSI dataset (red circles), both equations are applicable to the DMSI catalog (orange circles) with a lower resolution. Earthquakes with $M_{0}>10^{15} \mathrm{Nm}(\mathrm{M}>4)$ have a smaller MMSI than the values predicted because the $M>4$ events are partially contaminated by the clustered small events.

Equations 3 and 4 correspond to the empirical maximum and minimum b-values of 1.5 and 0.5 (e.g., Wiemer and Benoit 1996), respectively, which indicates that the dimensions of slip and rupture are complex and that the dimensions probably play an important role in determining the MO-SI coefficient. The recorded events are likely accompanied by two- or three-dimensional slips dominated by Eq. 3 or 4 . In addition, $\mathrm{M}<4$ (small size) earthquakes are likely more two- and three-dimensional than $M>4$ events due to their smaller b-values. The range of b-values from $0.5-1.5$ for earthquakes has also been estimated in other regions, such as Alaska (Freymueller et al. 2008), South Asia (Kayal 2008) and Yellowstone (Farrell et al. 2009).

\section{Comparison with the seismic sequences}

The deviation of the seismic slip rate from the average seismic slip rate may account for the long-term variation in the value of $c$, as seen from the gap size between the pink and cyan curves of $M_{0}$ and MSI, respectively, in Figs. 2, 3, 4, 5, 6, 7, 8. This deviation possibly suggests coseismic slip or a slip deficit along a seismogenic fault. A diverging trend of the two curves appears after the 2011 Tohoku-oki great earthquakes at the seismically dense spheres close to Tohoku, such as seismically dense spheres 20, 24 and 40. This trend might suggest a decreasing seismic slip rate, from the coseismic peak to a postseismic normal rate, possibly representing fault recoupling. This kind of aftershock sequence has also been found to follow the modified Omori law $\mathrm{n}(\mathrm{t})=\mathrm{K}(\mathrm{t}+\mathrm{c})^{-\mathrm{p}}$ (Utsu et al. 1995) or epidemic-type aftershock sequence model (Ogata et al. 2003). Most seismic sequences experience an immediate increase in Mo and an immediate decrease in SI and a subsequent decay as Mo and SI approach prequake durations, which show that the degree of seismic variation in Mo and SI is a function of the radius $(r)$ and nucleation zone size $\left(h^{*}\right)$ of the velocity-weakening patch (e.g., Chen and Lapusta 2009; Chen et al. 2010; Uchida et al. 2015). If we use $\mathrm{T}=1 / \mathrm{n}(\mathrm{t})$ to replace $\mathrm{T}$ in Eq. 3, then we easily have $\mathrm{n}(\mathrm{t}) \mathrm{M}_{0}(\mathrm{t})=\mu \mathrm{L}^{2} \mathrm{v}$, and $\log \mathrm{n}(\mathrm{t})+\log \mathrm{M}_{0}(\mathrm{t})=\log \mu \mathrm{L}^{2} \mathrm{v}$, which reasonably interprets the simultaneous decay of Mo and SI (T) for most of the seismic sequences. The sparsely distributed stage of seismicity usually accompanies a narrow gap between the pink and cyan curves and is interpreted as a slip deficit (e.g., Fig. 2, before September 2001), indicating a-value of $\log \mu \mathrm{L}^{2} \mathrm{v}$.

\section{Comparison with the seismic rate and global seismic moment}

Based on the calculated background seismicity rate $(\mathrm{Mw}>4.5)$ for 117 subduction zones globally, a proportionality relationship, in which the relative plate motion velocity correlates with the seismicity rate, has been demonstrated (Ide 2013). If the total seismic energy release rate is hypothesized to be less variable, then Eq. 4 is equivalent to

$$
R \propto\left(\mu^{-1} \tau^{2} M_{o t}\right)^{-\frac{1}{3}} V,
$$

where $R=1 / T$ is the seismic rate $\left(\mathrm{s}^{-1}\right), V$ is the plate seismic load rate $(\mathrm{m} / \mathrm{s})$, and $M_{o t}$ is the total seismic moment $(\mathrm{Nm})$ during a long period in the subduction zone or the global system. The advantage of Eq. 5 is a potential proportionality of the seismic rate with the relative plate motion velocity.

\section{Calculation of the scaling coefficient in Japan}

We further enlarged the modeled region to include all of Japan using the same catalog (Fig. 9). If a radius of $20 \mathrm{~km}$ and a threshold of ten thousand events for each sphere are applied, the resulting distribution of the c-values of the earthquake moment rates is shown in Fig. 9. Along offshore Tohoku and the Japan Trench, high c-values are identified despite other parts of inland Japan showing 


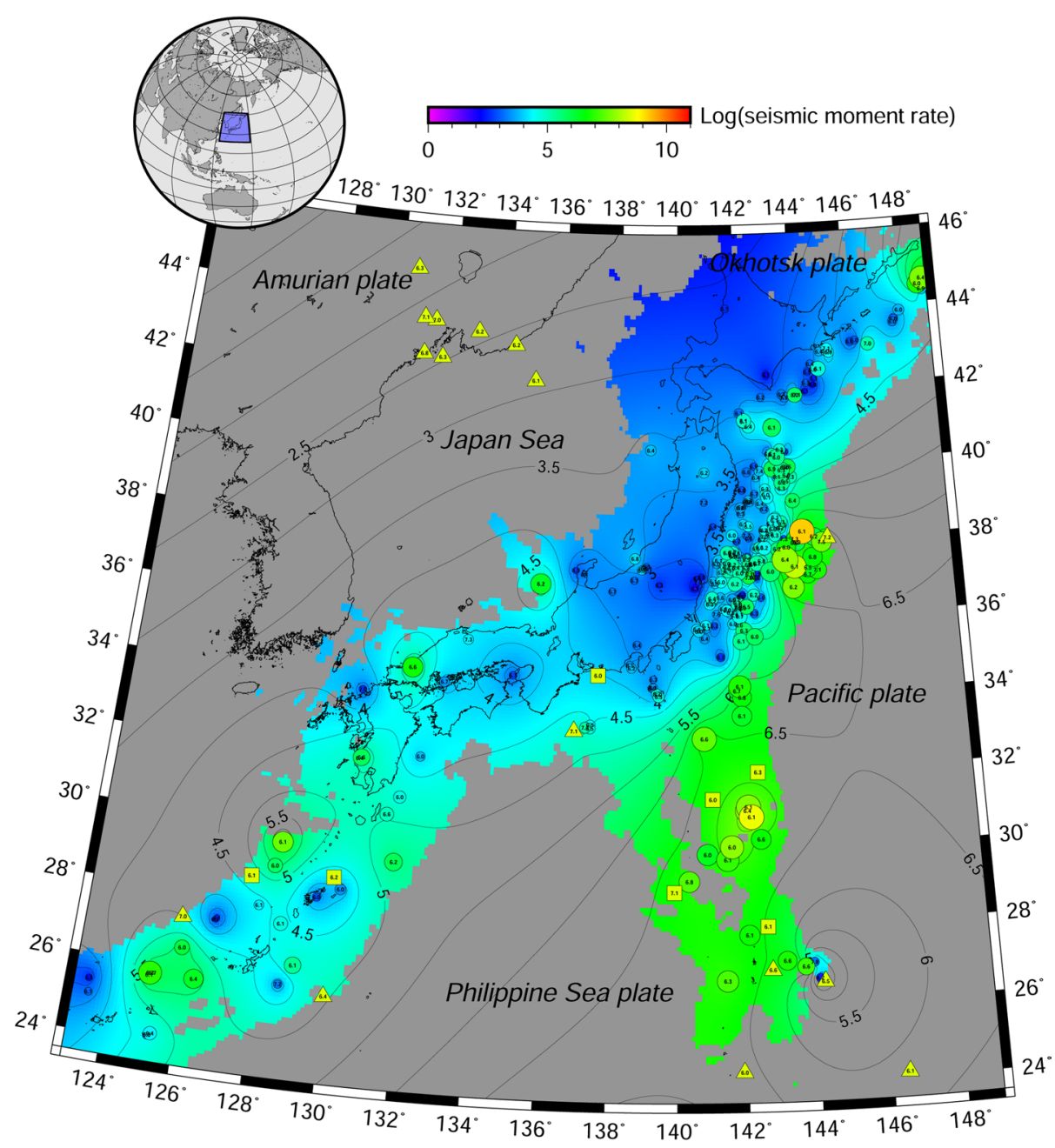

Fig. 9 Distribution of the logarithm of the seismic moment rate $\left(\log ^{c}\right)$ obtained by the MMSI method and compared with the hypocenters of recorded M5 + earthquakes from 1997 to 2015 at depths shallower than $60 \mathrm{~km}$ using a threshold of 10,000 events for each seismically dense sphere. The color indicates the seismic moment rate $\left(\log ^{c}\right)$ value in and around Japan in this study. The squares and triangles indicate that the seismically dense spheres are unable to calculate the MMSI due to insufficient foreshocks before (squares) or after (triangles) December 31, 1998, while the circles indicate the seismically dense spheres with sufficient foreshocks to calculate the MMSI. The number inside the squares, triangles, and circles indicates the magnitude of M5+ earthquakes. The size of the squares and triangles is fixed. The radii of the circles indicate the ratio value of the smallest seismic moment rate of the foreshocks versus the seismic moment rate of the M5+ mainshock. Small radii of circles indicate that the M5+ earthquake (usually landward) occurred immediately after a large seismic interval or the foreshocks are associated with a small seismic interval

a predominantly low c-value. This difference might be caused by the different plate seismic load rates and the different rigidities or fragilities of the continental crust, according to Eq. 3. In contrast, along with the Izu-Bonin island arc chain, the high dominant c-value is possibly caused by the thinner Philippine Sea (PHS) oceanic crust over the subducted Pacific (PAC) plate. Figure 10 depicts the calculated extrapolated distribution minimum c-values for every sphere from 2009 to 2010, implying a larger c-value (shorter seismic interval) for the regions abundant in M5+earthquakes. This provides a potentially important way to study the details of the featured regional seismicity. Although the seismic load rates and c-values vary greatly in seismogenic zones, the regional seismicity is probably controlled by fault interaction properties such as fault strength and patch size (e.g., Taira et al. 2009; Chen et al. 2010) that are influenced by a tectonic background, which has the potential to provide insight into earthquake prediction provided that a sufficient number of recorded earthquakes enable such a study. 


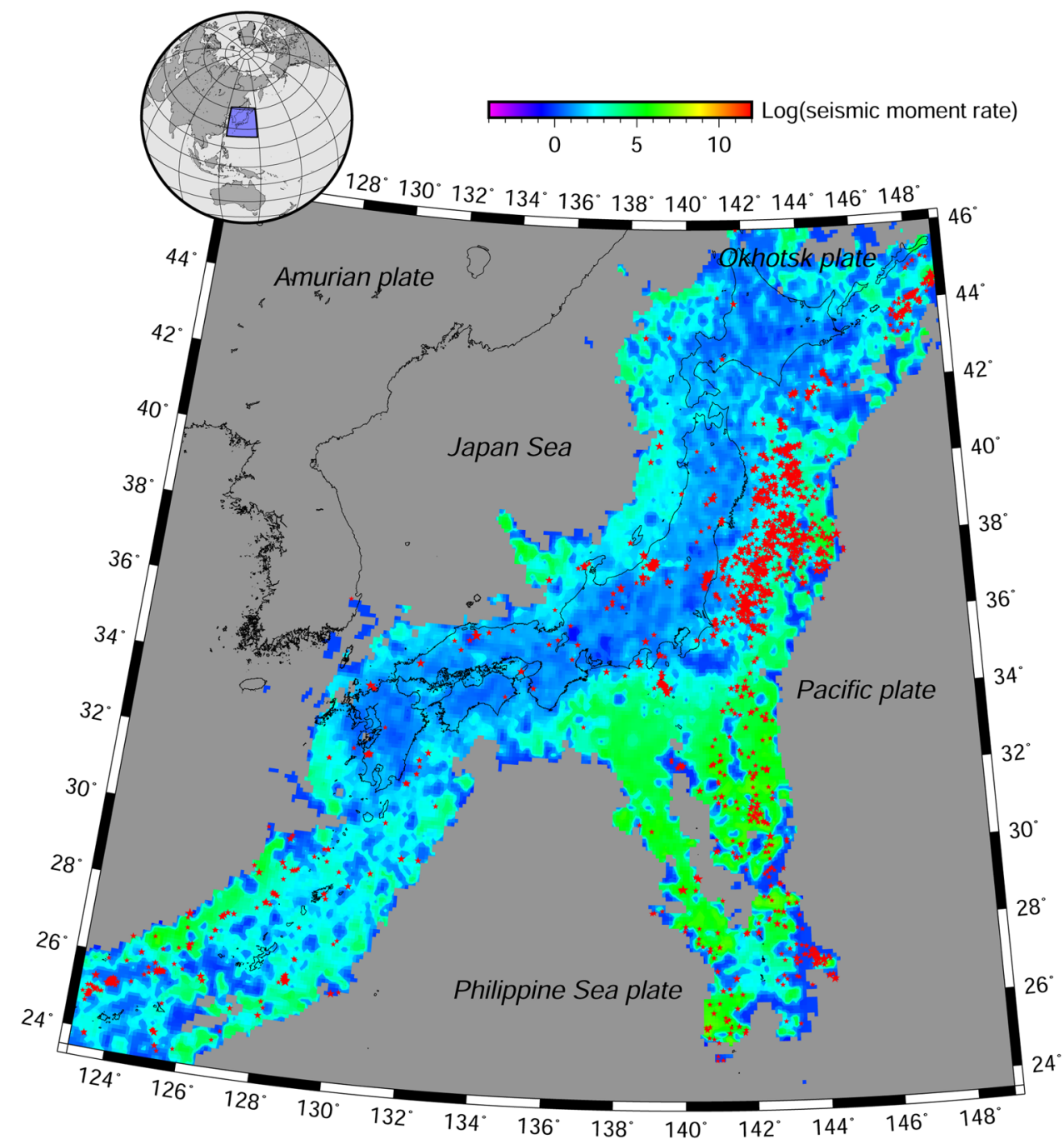

Fig. 10 Distribution of the seismic moment rate $\left(\log ^{c}\right)$ value from 2009 to 2010 at a depth $<30 \mathrm{~km}$ using a threshold of 10,000 events for each seismically dense sphere compared to the epicenters of M5 + earthquakes recorded. The color indicates the seismic moment rate from 2009 to 2010 at a depth $<30 \mathrm{~km}$. The red stars indicate the epicenters of M5 + earthquakes

\section{Conclusions}

We use 3-D seismically dense spheres and maximum seismic interval methods to analyze a large number of seismic events recorded in the 49 most seismogenic regions in Japan and obtain the following results from a unique 3-D perspective:

(1) Analysis of a large number of recorded seismic events shows that the seismic moment is generally proportional to the seismic interval for regular earthquakes. The seismic moment rate is approximately $10^{4 \sim 6}$ in these seismically active zones in Japan.

(2) The vertical dimension of depth plays an important role in the Mo-SI relationship as well as the vari- ance in 3-D seismic moment-interval magnitudes. 3-D seismic fault slips influence the variation in the power coefficient of the seismic interval with the variation in the seismic moment.

(3) Recorded M5+ earthquakes from 1997 to 2015 in Japan preferentially recurred at plate convergence zones with large seismic moment rates. The seismic moment rate varies with area and depth in affecting the regional earthquake recurrence frequency.

\section{Supplementary Information}

The online version contains supplementary material available at https://doi. org/10.1186/s40562-020-00173-5. 
Additional file 1. "Explanation for Eq. 1".

\section{Acknowledgments}

We thank Kenji Satake and two anonymous reviewers for the constructive comments to improve this paper. We also thank the Japan Meteorological Agency for the unified hypocenter data catalog and Smith and Sandwell for the Etopo digital elevation model. The figures were created with Generic Mapping Tools (GMT, Wessel and Smith 1998). This work was partly supported by funds from the Institute of Tibetan Plateau Research, Chinese Academy of Sciences, and the CAS Pioneer Hundred Talents Program.

\section{Authors' contributions}

YJ set up the numerical model and took the lead in writing the manuscript, performed the numerical modeling on a supercomputing facility, processed the modeling results and prepared the figures. SY provided comments and revisions. Both authors read and approved the final manuscript.

\section{Funding}

This work was partly supported by funds from the Institute of Tibetan Plateau Research, Chinese Academy of Sciences, and the CAS Pioneer Hundred Talents Program.

\section{Availability of data and materials}

The unified hypocenter data catalog used in this study was searched using http://www.data.jma.go.jp/svd/eqev/data/bulletin/hypo.html. The Etopo digital elevation model (Smith and Sandwell 1997) is available at https:// www.ngdc.noaa.gov $/ \mathrm{mgg} / \mathrm{global} / \mathrm{etopo} 2 . \mathrm{html}$. The figures were created with Generic Mapping Tools (GMT, version 4.5.7, Wessel and Smith, 1998) available at https://www.soest.hawaii.edu/gmt/. The data for this paper are available at the DataOne dataset https://doi.org/10.15146/R30M3W.

\section{Competing interests}

All the authors certify that they have no affiliations with or involvement in any organization or entity with any financial interest (such as honoraria; educational grants; participation in speakers' bureaus; membership, employment, consultancies, stock ownership, or other equity interest; and expert testimony or patent-licensing arrangements) or nonfinancial interest (such as personal or professional relationships, affiliations, knowledge or beliefs) in the subject matter or materials discussed in this manuscript.

\section{Author details}

${ }^{1}$ Center of Excellence in Tibetan Plateau Earth Science, Chinese Academy of Sciences, Beijing 100101, China. ${ }^{2}$ Key Laboratory of Continental Collision and Plateau Uplift, Institute of Tibetan Plateau Research, Chinese Academy of Sciences, Beijing 100101, China. ${ }^{3}$ University of Chinese Academy of Sciences, Beijing 100049, China. ${ }^{4}$ Research Center for Urban Safety and Security, Kobe University, Rokkodai-cho 1-1, Nada ward, Kobe 657-8501, Japan. ${ }^{5}$ Department of Planetology, Graduate School of Science, Kobe University, Rokkodai-cho 1-1, Nada ward, Kobe 657-8501, Japan.

\section{Received: 20 October 2020 Accepted: 18 December 2020}

Published online: 12 January 2021

\section{References}

Chen T, Lapusta N (2009) Scaling of small repeating earthquakes explained by interaction of seismic and aseismic slip in a rate and state fault model. J Geophys Res. https://doi.org/10.1029/2008JB005749

Chen KH, Bürgmann R, Nadeau RM, Chen T, Lapusta N (2010) Postseismic variations in seismic moment and recurrence interval of repeating earthquakes. Earth Planet Sci Lett 299(1):118-125

Farrell J, Husen S, Smith RB (2009) Earthquake swarm and b-value characterization of the Yellowstone volcano-tectonic system. J Volcanol Geoth Res 188:260-276

Freymueller JT, Haeussler PT, Wesson RL, Ekström G (2008) Active tectonics and seismic potential of Alaska. American Geophysical Union, Washington, p 431

Gutenberg B, Richter C (1956) Seismicity of the earth and associated phenomena, 2nd edn. Princeton University Press, Princeton, p 310

Hanks TC, Kanamori H (1979) A moment magnitude scale. J Geophys Res 84:2348
Ide S (2013) The proportionality between relative plate velocity and seismicity in subduction zones. Nat Geosci 6(9):780-784

JiY, Yoshioka S, Matsumoto T (2016) Three-dimensional numerical modeling of temperature and mantle flow fields associated with subduction of the Philippine Sea plate, southwest Japan. J Geophys Res Solid Earth 121(6):4458-4482

Kanamori H (1983) Magnitude scale and quantification of earthquakes. Tectonophysics 93:185-199

Katsumata A (1996) Comparison of magnitudes estimated by the Japan meteorological agency with moment magnitudes for intermediate and deep earthquakes. B Seismol Soc Am 86:832-842

Kayal JR (2008) Microearthquake seismology and seismotectonics of South Asia. Springer, Netherlands, p 147

Lengline O, Marsan D (2009) Inferring the coseismic and postseismic stress changes caused by the $2004 \mathrm{Mw}=6$ Parkfield earthquake from variations of recurrence times of microearthquakes. J Geophys Res 114:B10303. https :/doi.org/10.1029/2008JB006118

Leonard M (2010) Earthquake fault scaling: Self-consistent relating of rupture length, width, average displacement, and moment release. Bull Seismol Soc Am 100(5A):1971-1988. https://doi.org/10.1785/0120090189

Nakajima J, Hasegawa A (2007) Subduction of the Philippine Sea plate beneath southwestern Japan: Slab geometry and its relationship to arc magmatism. J Geophys Res 112:B08306

Nanjo KZ, Ishibe T, Tsuruoka H, Schorlemmer D, Ishigaki Y, Hirata N (2010) Analysis of the completeness magnitude and seismic network coverage of Japan. Bull Seism Soc Am 100(6):3261-3268. https://doi.org/10.1785/0120100077

Ogata Y, Jones LM, Toda S (2003) When and where the aftershock activity was depressed: contrasting decay patterns of the proximate large earthquakes in southern California. J Geophys Res 108:2318. https://doi. org/10.1029/2002JB002009

Peng Z, Vidale JE, Marone C, Rubin A (2005) Systematic variations in recurrence interval and moment of repeating aftershocks. Geophys Res Lett. https:// doi.org/10.1029/2005GL022626

Schaff DP, Beroza GC (2004) Coseismic and postseismic velocity changes measured by repeating earthquakes. J Geophys Res Solid Earth. https://doi. org/10.1029/2004JB003011

Smith WHF, Sandwell DT (1997) Global seafloor topography from satellite altimetry and ship depth soundings. Science 277:1957-1962

Taira T, Silver PG, Niu F, Nadeau RM (2009) Remote triggering of fault-strength changes on the San Andreas fault at Parkfield. Nature 461:636-639. https:// doi.org/10.1038/nature08395

Templeton DC, Nadeau RM, Bürgmann R (2009) Distribution of postseismic slip on the Calaveras fault, California, following the 1984 M6. 2 Morgan Hill earthquake. Earth Planet Sci. Lett. 277(1-2):1-8

Uchida N, Hasegawa A, Matsuzawa T, Igarashi T (2004) Pre- and post-seismic slip on the plate boundary off Sanriku NE Japan associated with three interplate earthquakes as estimated from small repeating earthquake data. Tectonophysics 385:1-15

Uchida N, Shimamura K, Matsuzawa T, Okada T (2015) Postseismic response of repeating earthquakes around the 2011 Tohoku-oki earthquake: Moment increases due to the fast loading rate. J Geophys Res Solid Earth. https://doi. org/10.1002/2013JB010933

Ueno H, Hatakeyama S, Aketagawa T, Funasaki J, Hamada N (2002) Improvement of hypocenter. determination procedures in the Japan Meteorological Agency (in Japanese). Quart J Seis 65:123-134

Utsu T (1983) Relationships between earthquake magnitude scales. Bull Earthq Res Inst 57:465-497

Utsu T, Ogata Y, Matsu'ura RS (1995) The centenary of the Omori formula for a decay law of aftershock activity. J Phys Earth 43:1-33

Weng $\mathrm{H}$, Yang $\mathrm{H}$ (2017) Seismogenic width controls aspect ratios of earthquake ruptures. Geophys Res Lett 44(6):2725-2732. https://doi.org/10.1002/2016G L072168

Wessel P, Smith WHF (1998) New, improved version of the generic mapping tools released. EOS Trans AGU 79:579

Wiemer S, Benoit JP (1996) Mapping the B-value anomaly at $100 \mathrm{~km}$ depth in the Alaska and New Zealand Subduction Zones. Geophys Res Lett 23(13):1557-1560

\section{Publisher's Note}

Springer Nature remains neutral with regard to jurisdictional claims in published maps and institutional affiliations. 